\title{
Development and Validation of a Stability-Indicating HPTLC Method for Analysis of Rasagiline Mesylate in the Bulk Drug and Tablet Dosage Form
}

\author{
Singaram Kathirvel, ${ }^{1}$ Suggala Venkata Satyanarayana, ${ }^{2}$ and Garikapati Devalarao ${ }^{3}$ \\ ${ }^{1}$ Department of Pharmaceutical Analysis, Hindu College of Pharmacy, Amaravathi Road, Guntur 522002, India \\ ${ }^{2}$ Department of Chemical Engineering, JNTU College of Engineering, Anantapur 515002, India \\ ${ }^{3}$ Department of Pharmaceutical Analysis, KVSR Siddhartha College of Pharmaceutical Sciences, Vijayawada 520008, India
}

Correspondence should be addressed to Garikapati Devalarao, devalarao2007@gmail.com

Received 2 May 2011; Revised 18 July 2011; Accepted 2 October 2011

Academic Editor: Wenkui Li

Copyright ( $) 2012$ Singaram Kathirvel et al. This is an open access article distributed under the Creative Commons Attribution License, which permits unrestricted use, distribution, and reproduction in any medium, provided the original work is properly cited.

\begin{abstract}
A simple and sensitive thin-layer chromatographic method has been established for analysis of rasagiline mesylate in pharmaceutical dosage form. Chromatography on silica gel $60 \mathrm{~F}_{254}$ plates with $6: 1: 2(\mathrm{v} / \mathrm{v} / \mathrm{v})$ butanol-methanol water as mobile phase furnished compact spots at $R_{f} 0.76 \pm 0.01$. Densitometric analysis was performed at $254 \mathrm{~nm}$. To show the specificity of the method, rasagiline mesylate was subjected to acid, base, neutral hydrolysis, oxidation, photolysis, and thermal decomposition, and the peaks of degradation products were well resolved from that of the pure drug. Linear regression analysis revealed a good linear relationship between peak area and amount of rasagiline mesylate in the range of 100-350 ng/band. The minimum amount of rasagiline mesylate that could be authentically detected and quantified was 11.12 and $37.21 \mathrm{ng} / \mathrm{band}$, respectively. The method was validated, in accordance with ICH guidelines for precision, accuracy, and robustness. Since the method could effectively separate the drug from its degradation products, it can be regarded as stability indicating.
\end{abstract}

\section{Introduction}

Rasagiline mesylate (Figure 1) is a chemical inhibitor of the enzyme monoamine oxidase type-B which has a major role in the inactivation of biogenic and diet-derived amines in the central nervous system. Rasagiline is a propargylamine-based drug indicated for the treatment of idiopathic Parkinson's disease. It is designated chemically as (R)-N-(prop-2-ynyl)2,3-dihydro-1H-inden-1-amine. Rasagiline is freely soluble in water and ethanol and sparingly soluble in isopropyl alcohol. It is a chiral compound with one asymmetric carbon atom in a five-member ring with an absolute R-configuration which is produced as single enantiomer [1].

There are many methods reported in the literature for analysis of rasagiline mesylate, for example, GC-MS [2], HPLC methods [3-5], LC-MS/MS in human plasma [6], and spectrophotometric methods [7, 8]. However, no available densitometric method for the simultaneous separation of rasagiline mesylate from degradation products has been reported. Hence, the objective of the present study is to develop and validate a new HPTLC method for the estimation of rasagiline mesylate in bulk drug and its dosage form.

Today, HPTLC is rapidly becoming a routine analytical technique due to its advantages of low operating costs high sample throughput, and need for minimum sample preparation. The major advantage of HPTLC is that several samples can be run simultaneously using a small quantity of mobile phase unlike HPLC, thus reducing the analysis time and cost per analysis [9]. Accordingly, the aim of the present study was to establish the inherent stability of rasagiline mesylate through stress studies under a variety of ICH recommended test conditions $[10,11]$ and to develop a stability-indicating HPTLC assay [12]. The proposed method was validated according to the $\mathrm{ICH}$ guidelines [13]. 


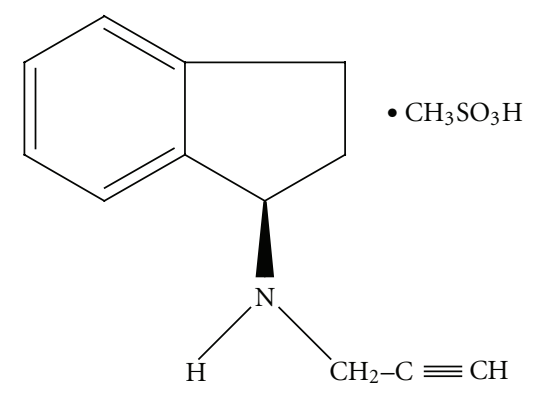

Figure 1: Structure of rasagiline mesylate.

\section{Experimental}

2.1. Materials and Reagents. Rasagiline mesylate was obtained from Orchid Pharmaceuticals Ltd (Chennai, India). It was used without further purification and certified to contain 99.67\% (w/w) on dry weight basis. Rasagiline Mesylate Pharmaceutical preparation, Rasipron was purchased from a local drug store; it contained $1 \mathrm{mg}$ active material. The other chemicals and reagents used were of AR grade and procured from S.D. Fine-Chem (New Delhi, India).

2.2. HPTLC Instrumentation. Chromatography was performed on $10 \mathrm{~cm} \times 10 \mathrm{~cm}$ aluminium foil plates precoated with $0.2 \mathrm{~mm}$ layers of silica gel $60 \mathrm{~F}_{254}$ (E. Merck, Germany). Before use, the plates were prewashed by development with methanol then dried in the current of dry air and activated at $60^{\circ} \mathrm{C}$ for $5 \mathrm{~min}$. Samples were applied as bands $6 \mathrm{~mm}$ wide, $15 \mathrm{~mm}$ apart, by use of a Camag (Switzerland) Linomat 5 equipped with a microlitre syringe. A constant application rate of $150 \mathrm{~nL} \mathrm{~s}^{-1}$ was used. Butanol methanol water $6: 1: 2$ $(\mathrm{v} / \mathrm{v} / \mathrm{v})$ was used as the mobile phase. Linear ascending development was performed in a twin-trough glass chamber previously saturated with mobile phase vapour for $30 \mathrm{~min}$ at room temperature $\left(\mathrm{RT}, 25 \pm 2{ }^{\circ} \mathrm{C}\right.$ ) and relative humidity 60 $\pm 5 \%$. The development distance was approximately $80 \mathrm{~mm}$. After development, the plates were dried in current of air by use of an air dryer. Densitometric scanning, at $254 \mathrm{~nm}$, was performed with a Camag TLC scanner 3 in absorbance mode. The source of radiation was a deuterium lamp emitting a continuous UV spectrum in the range 190-400 $\mathrm{nm}$.

2.3. Calibration Plots of Rasagiline Mesylate. A stock solution containing $100 \mu \mathrm{g} / \mathrm{mL}$ of rasagiline mesylate was prepared by dissolving an accurately weighed $10 \mathrm{mg}$ portion of the drug in methanol in $100 \mathrm{~mL}$ volumetric flask. Different volumes of stock solution $(1,1.5,2,2.5,3,3.5 \mu \mathrm{L})$ were spotted on an HPTLC plate in triplicate to obtain concentrations of 100, $150,200,250,300$, and $350 \mathrm{ng} /$ band of rasagiline mesylate, respectively. The data of peak area versus drug concentration were treated by linear least-squares regression.

\subsection{Method Validation}

2.4.1. Precision. The precision of the method was verified by repeatability and intermediate precision studies. Repeatability studies were performed by analyzing three different concentrations (100, 200, and $300 \mathrm{ng} / \mathrm{spot})$ of the drug by six times on the same day. The intermediate precision of the method was checked by repeating on three different days.

2.4.2. Robustness. The analytical conditions were deliberately changed, by introducing small changes in mobile phase composition $( \pm 2 \%)$, mobile phase volume $( \pm 2 \%)$, chamber saturation period $( \pm 10 \%)$, and development distance $( \pm 10 \%)$, and time from application to development $(0,10$, $15,20 \mathrm{~min})$ and time from development to scanning $(0,30$, $60,90 \mathrm{~min}$ ) were carried out.

2.4.3. $L O D$ and LOQ. The method was used to determine the LOD and LOQ. Blank methanol was spotted six times, and the SD $\left(S_{b}\right)$ of the peak area of the blanks was calculated. The limits were determined from the slope $(S)$ of the calibration plot and the SD of the response for the blank sample $\left(S_{b}\right)$ by use of the formula:

$$
\mathrm{LOD}=3.3 \times \frac{S_{b}}{S}, \quad \mathrm{LOQ}=10 \times \frac{S_{b}}{S} .
$$

2.4.4. Accuracy. To check the degree of accuracy of the method, recovery studies were performed in triplicate by standard addition method at 50, 100, and 150\%. Known amount of standard rasagiline mesylate was added to preanalysed samples and was subjected to the proposed HPTLC method.

2.4.5. Specificity. The specificity of the method was determined by comparing the results for the standard drug and the sample. The peak purity of the sample was assessed by comparing the spectra at peak start, peak apex, and peak end positions of the band.

2.4.6. Forced Degradation Studies of Rasagiline Mesylate. A stock solution containing $10 \mathrm{mg}$ rasagiline mesylate in $100 \mathrm{~mL}$ methanol $(100 \mu \mathrm{g} / \mathrm{mL})$ was used for forced degradation to provide an indication of the stability-indicating ability and specificity of the proposed method. Studies of acid-induced decomposition were performed by exposing the solution of the drug to $5 \mathrm{M}$ hydrochloric acid by heating the solution under reflux at $80^{\circ} \mathrm{C}$ for $5 \mathrm{~h}$. Studies of baseinduced decomposition were performed in $5 \mathrm{M}$ sodium hydroxide, and the solution was heated under reflux for $3 \mathrm{~h}$ at $80^{\circ} \mathrm{C}$. The resulting solutions were applied on TLC plate in triplicate $(2.5 \mu \mathrm{L}$ each, i.e. $250 \mathrm{ng}$ /band). The plate was chromatographed as described above. Oxidative degradation was studied by refluxing the drug solution to $30 \%$ hydrogen peroxide for $4 \mathrm{~h}$ at $80^{\circ} \mathrm{C}$. The resulting solution was applied to TLC plates such that $250 \mathrm{ng}$ per band was applied to the plates. Neutral hydrolysis was carried out by accurately weighing $25 \mathrm{mg}$ of the drug in $25 \mathrm{~mL}$ HPLC grade water, and the solution was refluxed for $12 \mathrm{hrs}$ at $50^{\circ} \mathrm{C}$. Appropriate aliquot was taken from the above solution and diluted with methanol to obtain a final concentration of $100 \mathrm{ng} / \mu \mathrm{L}$. The resultant solution $(2.5 \mu \mathrm{L})$ was applied to TLC plate ( $250 \mathrm{ng} / \mathrm{spot}$ ), and the chromatogram was run to evaluate the degradation effect. Similarly, dry heat degradation also 
carried out by placing the standard drug in solid form in an oven at $100^{\circ} \mathrm{C}$ for $10 \mathrm{hrs}$. Rasagiline mesylate $1 \mathrm{mg}$ was accurately weighed and separately dissolved in methanol in $10 \mathrm{~m}$ L volumetric flask. The resultant solution was applied to TLC plate in such a way that final concentration achieved was $250 \mathrm{ng} / \mathrm{spot}$. The photochemical stability of the drug was also studied by exposing the stock solution to direct sunlight $(60,000-70,000$ lux $)$ for $24 \mathrm{~h}$ on a wooden plank and kept on terrace. The solution ( $2.5 \mu \mathrm{L}$, equivalent to $250 \mathrm{ng} / \mathrm{band})$ was then applied to TLC plates, and densitograms were obtained as described above. The densitogram was run in triplicate in all the conditions to evaluate the degradative effect.

\subsection{Analysis of Rasagiline Mesylate in Tablet Dosage Form.} To determine the rasagiline mesylate content of conventional tablets, twenty tablets were weighed and powdered in a glass mortar. An amount of powder equivalent to $10 \mathrm{mg}$ rasagiline mesylate was transferred to a $100 \mathrm{~mL}$ volumetric flask, extracted with methanol, sonicated for $20 \mathrm{~min}$, and diluted to volume with same solvent. The resulting solution was filtered through a $0.45 \mu \mathrm{m}$ filter (Millifilter; Milford, MA; USA). The solution $(2.5 \mu \mathrm{L}, 250 \mathrm{ng}$ rasagiline mesylate) was applied in triplicate on an HPTLC plate for quantification using the proposed method.

\section{Results and Discussion}

3.1. Optimization of the Mobile Phase. Several solvent mixtures in different ratios were tested to obtain a compact band of rasagiline mesylate. Butanol:methanol: water $6: 1: 2 \mathrm{v} / \mathrm{v} / \mathrm{v}$ ) was found to give a compact band for rasagiline mesylate with an $R_{f}$ value of $0.76 \pm 0.01$ (Figure 2). This mobile phase gave good resolution for the separation of rasagiline mesylate, all degradation products, and was selected for the proposed stability-indicating method. Thirty minutes was found to be sufficient for saturation of the development chamber with the mobile phase vapor in order to obtain separation of the compounds. A $20 \mathrm{~mL}$ aliquot of mobile phase was used for a $20 \mathrm{~min}$ development over a distance of $80 \mathrm{~mm}$.

3.2. Calibration Plots of Rasagiline Mesylate. The linear regression analysis data for the calibration plots showed a good linear relationship $\left(r^{2}=0.9993 \pm 0.02\right)$ with respect to peak area in the concentration range of $100-350 \mathrm{ng} / \mathrm{band}$ (Figure 3). The mean values of the slope and intercept were $5.40 \pm 0.257$ and $23.15 \pm 1.791$, respectively, for densitometric analysis at $254 \mathrm{~nm}$ (Table 1 ).

\subsection{Method Validation}

3.3.1. Precision. The results of the repeatability and intermediate precision experiments are shown in Table 2. Inter precision studies were checked by both interday and intraday analysis. Interday analysis was carried out by repeating the experiments on three different days, whereas intraday analysis was done for 3 times on the same day. The developed method was found to be precise as the RSD values for

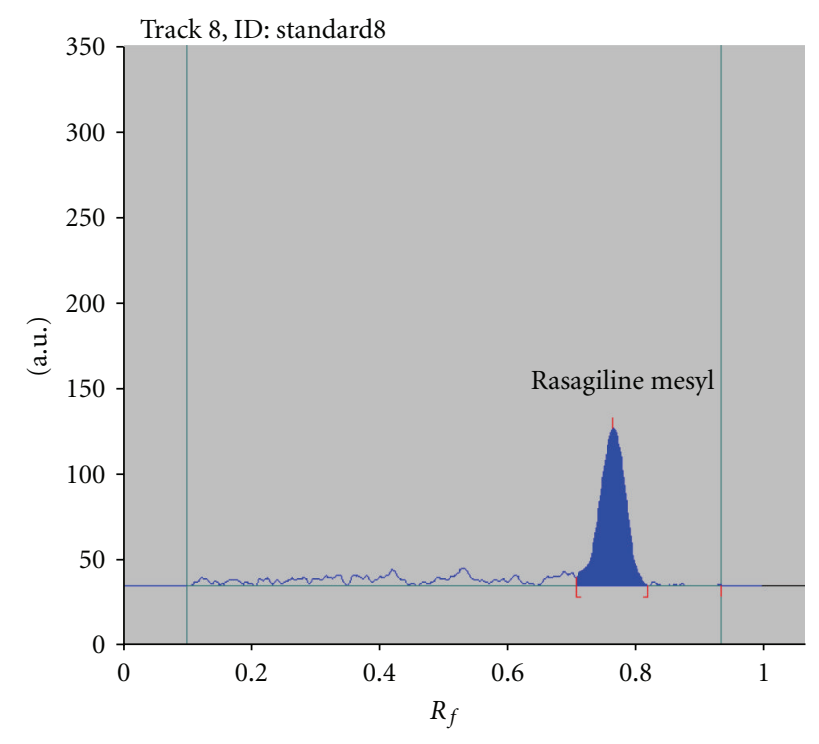

FIGURE 2: A typical HPTLC densitogram of rasagiline mesylate at $254 \mathrm{~nm}\left(R_{f}-0.76 \pm 0.01\right)$.

TABLE 1: Linear regression data for the calibration curves $(n=6)$.

\begin{tabular}{lc}
\hline Parameter & Rasagiline mesylate \\
\hline Linearity & $100-350 \mathrm{ng} / \mathrm{band}$ \\
Correlation coefficient, $r \pm \mathrm{SD}$ & $0.9993 \pm 0.02$ \\
Slope $\pm \mathrm{SD}$ & $5.40 \pm 0.257$ \\
Intercept \pm SD & $23.15 \pm 1.791$ \\
LOD, ng/band & 11.12 \\
LOQ, ng/band & 37.21 \\
\hline
\end{tabular}

repeatability and intermediate precision studies were $<2 \%$, respectively, as recommended by $\mathrm{ICH}$ guideline.

3.3.2. Robustness. The low values of RSD obtained after introducing small, deliberate changes in the mobile phase composition, mobile phase volume, chamber saturation time, time from application to development, and time from development to scanning in the developed HPTLC method indicated the robustness of the method. The \% RSD values of all the above-mentioned parameters are shown in Table 3.

3.3.3. LOD and LOQ. LOD and LOQ were determined by the SD method and were found to be 11.12 and $37.21 \mathrm{ng} / \mathrm{band}$, respectively (Table 1 ).

3.3.4. Accuracy. Accuracy of the method was obtained by recovery after spiking with 50,100 , and $150 \%$ of additional drug. The study was carried out in triplicate by standard addition method and found to be in the range of 99.10$101.0 \%$ (Table 4 ).

3.3.5. Specificity. The $R_{f}$ value $(0.76 \pm 0.01)$ of the sample and standard was almost identical, and spectra of the sample and the standard were superimposable. These results indicated the specificity of the method. 


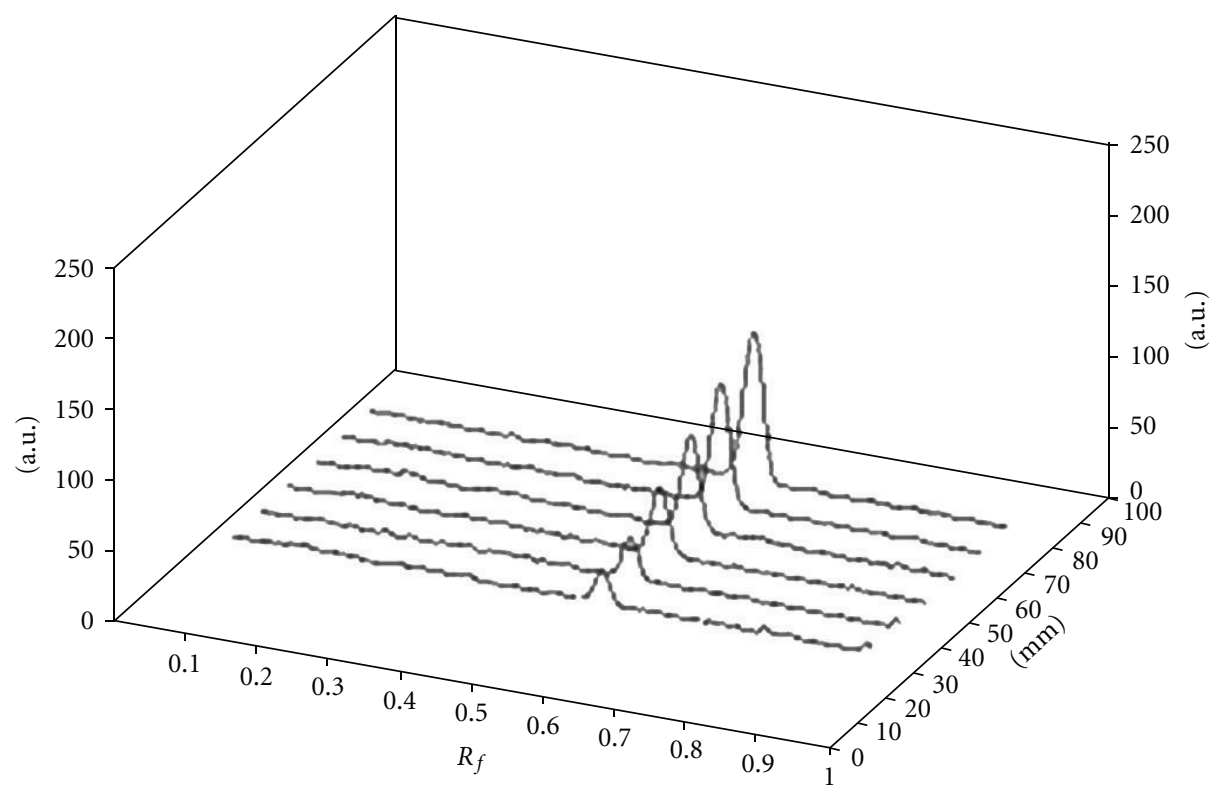

Figure 3: 3D representation of rasagiline mesylate sample. That is, track 1 is $100 \mathrm{ng} / \mathrm{band}$, track 2 is $150 \mathrm{ng} / \mathrm{band}$, track 3 is $200 \mathrm{ng} / \mathrm{band}$, track 4 is $250 \mathrm{ng} / \mathrm{band}$, track 5 is $300 \mathrm{ng} / \mathrm{band}$ and track 6 is $350 \mathrm{ng} / \mathrm{band}$.

TABle 2: Precision studies $(n=6)$.

\begin{tabular}{|c|c|c|c|c|}
\hline \multirow{2}{*}{ Concentration (ng/spot) } & \multicolumn{2}{|c|}{ Repeatability } & \multicolumn{2}{|c|}{ Intermediate precision } \\
\hline & Mean \pm SD (ng/spot) & $\operatorname{RSD}(\%)$ & Mean \pm SD (ng/spot) & RSD (\%) \\
\hline 100 & $98.20 \pm 1.95$ & 1.98 & $99.88 \pm 1.76$ & 1.76 \\
\hline 200 & $197.41 \pm 1.67$ & 0.84 & $196.50 \pm 1.50$ & 0.76 \\
\hline 300 & $298.77 \pm 1.08$ & 0.36 & $297.31 \pm 1.80$ & 0.60 \\
\hline
\end{tabular}

TABLE 3: Robustness testing $(n=6)$.

\begin{tabular}{lc}
\hline Parameters & \% RSD \\
\hline \% change in mobile phase & $0.72 \pm 0.01$ \\
Chamber saturation time & $0.74 \pm 0.02$ \\
Development distance & $0.76 \pm 0.01$ \\
Time from application to development & $0.75 \pm 0.02$ \\
Time from development to scanning & $0.74 \pm 0.01$ \\
\hline
\end{tabular}

TABLE 4: Recovery studies ${ }^{\mathrm{a}}$.

\begin{tabular}{lccc}
\hline $\begin{array}{l}\text { Excess drug } \\
\text { added to the } \\
\text { analyte (\%) }\end{array}$ & $\begin{array}{c}\text { Amount of } \\
\text { drug found } \\
\text { (ng) }\end{array}$ & \% Recovery & \% RSD \\
\hline 0 & 100.0 & 99.10 & 0.72 \\
50 & 151.6 & 101.06 & 0.49 \\
100 & 198.4 & 99.21 & 0.31 \\
150 & 252.2 & 100.88 & 0.44 \\
\hline
\end{tabular}

Matrix containing 100 ng of drug. ${ }^{a} n=6$.

3.3.6. Stability in Sample Solution. Solutions of two different concentrations (150 and $200 \mathrm{ng} / \mathrm{spot}$ ) were prepared from sample solution and stored at room temperature for 6.0, 12.0, $24.0,48.0$, and $72.0 \mathrm{~h}$, respectively. They were then applied on
TABLE 5: Stability of rasagiline mesylate in sample solution ${ }^{\mathrm{a}}$.

\begin{tabular}{lccc}
\hline Actual $(\mathrm{ng})$ & Area mean & Area range & $\%$ RSD \\
\hline & 813.1943 & $809.0121-819.5817$ & 0.58 \\
200 & 1120.8268 & $1116.3661-1129.7529$ & 1.58 \\
\hline${ }^{a_{n}=6 .}$ & & &
\end{tabular}

the same TLC plate after development, the chromatogram was evaluated as listed in (Table 5) for additional spots if any. The $\%$ RSD for the samples analyzed at different elapsed assay times was found to be $<2 \%$. Thus, the drug was stable in solution state. There was no indication of compound instability in the sample solution.

3.3.7. Forced Degradation Studies of Rasagiline Mesylate. The bands of degradation products were well resolved from the drug bands. The peak of rasagiline mesylate was not significantly shifted in the presence of degradation peaks, which indicated the stability-indicating property of the proposed method. The number of degradation products with their $R_{f}$ values under different stress conditions is shown in Table 6 .

The chromatograms, of the samples treated with acid, base, hydrogen peroxide, and sunlight showed well-separated bands of pure rasagiline mesylate as well as some additional 
TABLE 6: Degradation of rasagiline mesylate.

\begin{tabular}{lccc}
\hline Condition & Time (h) & $\begin{array}{c}\text { Recovery } \\
(\%)\end{array}$ & $\begin{array}{c}\text { (\%) value } \\
\text { of } \\
\text { degraded } \\
\text { products }\end{array}$ \\
\hline $\begin{array}{l}5 \mathrm{M} \mathrm{HCl} \\
\text { refluxed at } 80^{\circ} \mathrm{C}\end{array}$ & 5 & 47.50 & $7.53,44.96$ \\
$5 \mathrm{M} \mathrm{NaOH}$ & 3 & 46.92 & 22.92, \\
refluxed at $80^{\circ} \mathrm{C}$ & & & 11.96, \\
& & 63.30 & 18.75 \\
$\mathrm{H}_{2} \mathrm{O}_{2} 30 \% \mathrm{v} / \mathrm{v}$ & 4 & 100 & 21.37 \\
refluxed at $80^{\circ} \mathrm{C}$ & & & $\begin{array}{c}\text { None } \\
\text { detected }\end{array}$ \\
$\begin{array}{l}\text { Daylight } \\
\begin{array}{l}\text { Dry heat } \\
\text { degradation }\end{array}\end{array}$ & 10 & 100 & $\begin{array}{c}\text { None } \\
\text { detected }\end{array}$ \\
$\begin{array}{l}\text { Neutral hydrol- } \\
\text { ysis (Reflux at }\end{array}$ & 12 & & $\begin{array}{c}\text { None } \\
\text { 50 }\end{array}$ \\
\hline
\end{tabular}

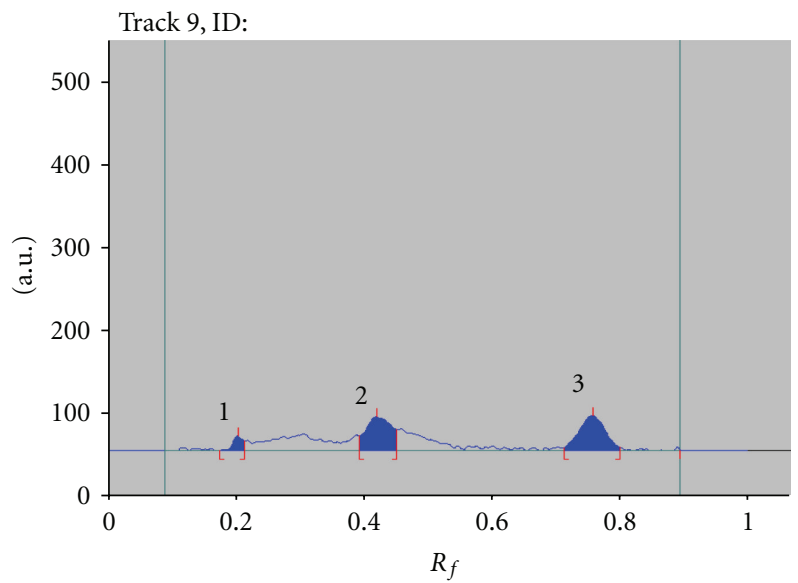

Figure 4: Densitogram of acid ( $5 \mathrm{NHCl}$, reflux for $5 \mathrm{~h}$, temp $80^{\circ} \mathrm{C}$ ) treated rasagiline mesylate; peak 1 (degraded $-R_{f}=0.20$ ), peak 2 (degraded $-R_{f}=0.42$ ), and peak 3 (rasagiline mesylate $-R_{f}=$ $0.76)$.

bands of the degradation products at different $R_{f}$ values (Table 6).

Drug recovery from the acid-stressed sample was found to be $47.50 \%$. Base-stressed samples showed recovery at the level of $46.92 \%$ (Table 6 ). The chromatogram of the aciddegraded sample showed two additional bands at $R_{f}$ values of 0.20 and 0.42 (Figure 4). The chromatogram of the basedegraded sample showed three additional bands at $R_{f}$ values of $0.26,0.52$, and 0.67 (Figure 5).

The chromatogram of the sample of rasagiline mesylate treated with $30 \%(\mathrm{v} / \mathrm{v}) \mathrm{H}_{2} \mathrm{O}_{2}$ had three additional bands at $R_{f} 0.43,0.53$, and 0.68 showing that rasagiline mesylate was susceptible to oxidation-induced degradation (Figure 6). Rasagiline mesylate remained stable in neutral, thermal, and photolytic conditions. All the above conditioned parameters showed recovery at the level of $100 \%$ suggesting that the

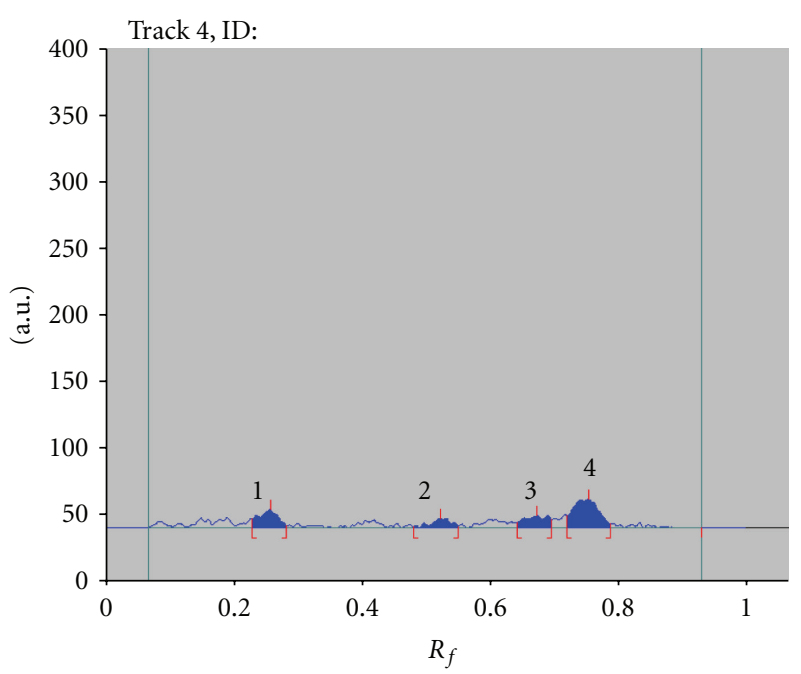

FIgURe 5: Densitogram of base $(5 \mathrm{~N} \mathrm{NaOH}$, reflux for $3 \mathrm{~h}$, temp $80^{\circ} \mathrm{C}$ ) treated rasagiline mesylate; peak 1 (degraded $-R_{f}=0.26$ ), peak 2 (degraded $\left.-R_{f}=0.52\right)$, peak 3 , (degraded $\left.-R_{f}=0.67\right)$, and peak 4 (rasagiline mesylate- $-R_{f}=0.76$ ).

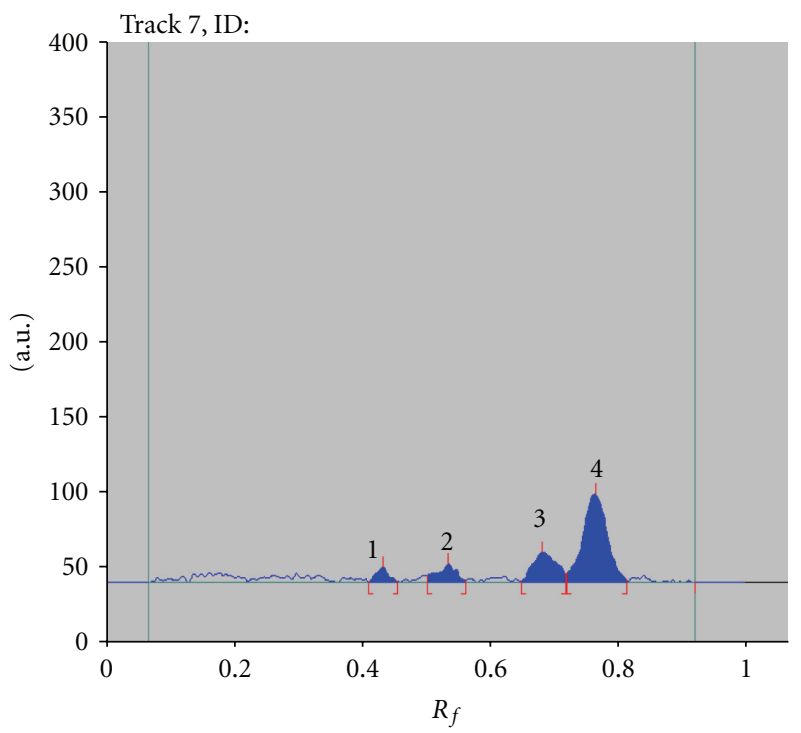

Figure 6: Densitogram of hydrogen peroxide (30\% v/v, reflux for $4 \mathrm{~h}$, temp $80^{\circ} \mathrm{C}$ ) treated rasagiline mesylate; peak 1 (degraded$R_{f}=0.43$ ), peak 2 (degraded $-R_{f}=0.53$ ), peak 3 (degraded$R_{f}=0.68$ ), and peak 4 (rasagiline mesylate $-R_{f}=0.76$ ).

drug does not undergo degradation in neutral, thermal, and photolytic conditions.

3.3.8. Analysis of Rasagiline Mesylate in Tablet Dosage Form. A single spot at $R_{f}-0.76$ was observed in the chromatogram of the drug samples extracted from tablets. There was no interference from the excipients commonly present in the tablets. The drug content was found to be $99.98 \%$ with a $\%$ RSD of $0.57(n=6)$. The low \% RSD value indicated the suitability of this method for routine analysis of rasagiline mesylate in pharmaceutical dosage form. 


\section{Conclusion}

The introduction of HPTLC to pharmaceutical analysis is a major step in quality assurance. This HPTLC technique is precise, specific, accurate, and stability indicating. Statistical analysis proved the method is suitable for analysis of rasagiline mesylate as the bulk drug and in a pharmaceutical formulation without interference from excipients. This is a typical stability-indicating assay, established in accordance with the recommendations of the ICH guidelines. The method can be used to determine the purity of a drug, and it is also proposed for analysis of drug and degradation products in stability samples obtained during industrial production.

\section{References}

[1] J. J. Chen, D. M. Swope, and K. Dashtipour, "Comprehensive review of rasagiline, a second-generation monoamine oxidase inhibitor, for the treatment of Parkinson's Disease," Clinical Therapeutics, vol. 29, no. 9, pp. 1825-1849, 2007.

[2] J. J. Thébault, M. Guillaume, and R. Levy, "Tolerability, safety, pharmacodynamics, and pharmacokinetics of rasagiline: a potent, selective, and irreversible monoamine oxidase type B inhibitor," Pharmacotherapy, vol. 24, no. 10, pp. 1295-1305, 2004.

[3] M. Fernández, E. Barcia, and S. Negro, "Development and validation of a reverse phase liquid chromatography method for the quantification of rasagiline mesylate in biodegradable PLGA microspheres," Journal of Pharmaceutical and Biomedical Analysis, vol. 49, no. 5, pp. 1185-1191, 2009.

[4] R. Narendrakumar, G. Nageswara Rao, and P. Y. Naidu, "Stability indicating RP-LC method for determination of rasagiline mesylate in bulk and pharmaceutical Dosage forms," International Journal of Applied Biology and Pharmaceutical Technology, vol. 1, no. 2, pp. 247-259, 2010.

[5] M. Vijayalakshmi, J. V. L. N. Seshagiri Rao, and A. Lakshmana Rao, "Development and validation of RP-HPLC method for the estimation of rasagiline tablet dosage forms," Rasayan Journal of Chemistry, vol. 3, no. 4, pp. 621-624, 2010.

[6] J. Chen, X. Duan, P. Deng, H. Wang, and D. Zhong, "Validated LC-MS/MS method for quantitative determination of rasagiline in human plasma and its application to pharmacokinetic studies," Journal of Chromatography B, vol. 873, no. 2, pp. 203208, 2008.

[7] G. Devalarao, S. Kathirvel, and S. V. Satyanarayana, "Simple spectrophotometric methods for the determination of rasagiline mesylate in pharmaceutical dosage form," Journal of Pharmacy Research, vol. 4, no. 1, pp. 61-62, 2011.

[8] B. Rama and K. Preeti, "UV Spectrophotometric method for the determination of rasagiline mesylate in bulk and pharmaceutical formulations," International Journal of Pharmaceutical Sciences Review and Research, vol. 5, no. 1, pp. 5-7, 2010.

[9] G. Y. S. K. Swamy, K. Ravikumar, L. K. Wadhwa, R. Saxena, and S. Singh, " $\left(2 R^{*}, 3 R^{*}, 6 S^{*}\right)-N, 6$-Bis(4-fluorophenyl)-2-(4hydroxyphenyl)-3,4,5,6-tetrahydro- $2 \mathrm{H}$-pyran-3-carboxamide," Acta Crystallographica Section E, vol. 61, no. 11, pp. 36083610, 2005.

[10] ICH, "Stability testing of new drug substances and products Q1A (R2)," in Proceedings of the International Conference on Harmonization, International Federation of Pharmaceutical Manufacturers and Association, Geneva, Switzerland, 2003.
[11] S. Singh and M. Bakshi, "Guidance on conduct of stress tests to determine inherent stability of drugs," Pharmacy Technician Online, vol. 24, pp. 1-14, 2000.

[12] M. Bakshi and S. Singh, "Development of validated stabilityindicating assay methods - critical review," Journal of Pharmaceutical and Biomedical Analysis, vol. 28, pp. 1011-1040, 2002.

[13] ICH Topic Q2 (R1), Validation of analytical procedures: Methodology, Geneva, The European Agency for the Evaluation of Medicinal Products, September 2005. 


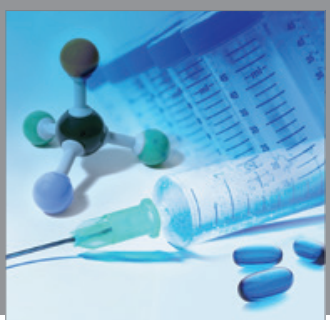

International Journal of

Medicinal Chemistry

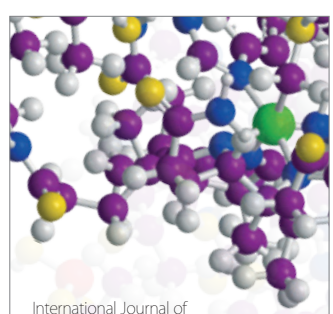

Carbohydrate Chemistry

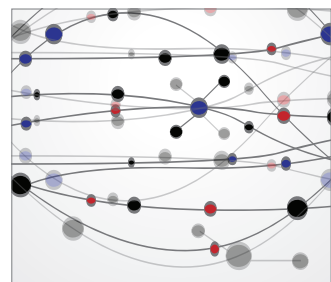

The Scientific World Journal
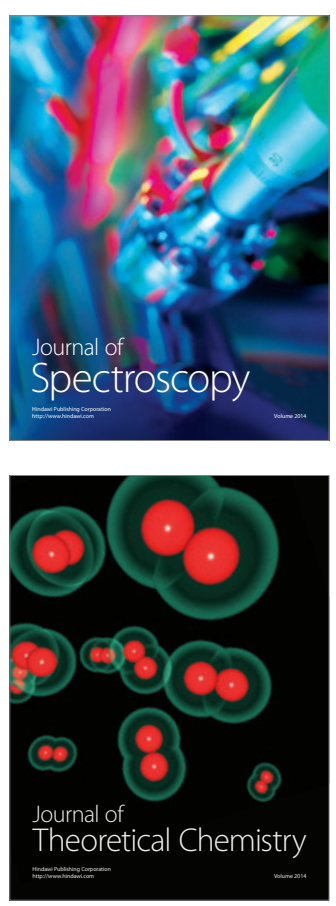
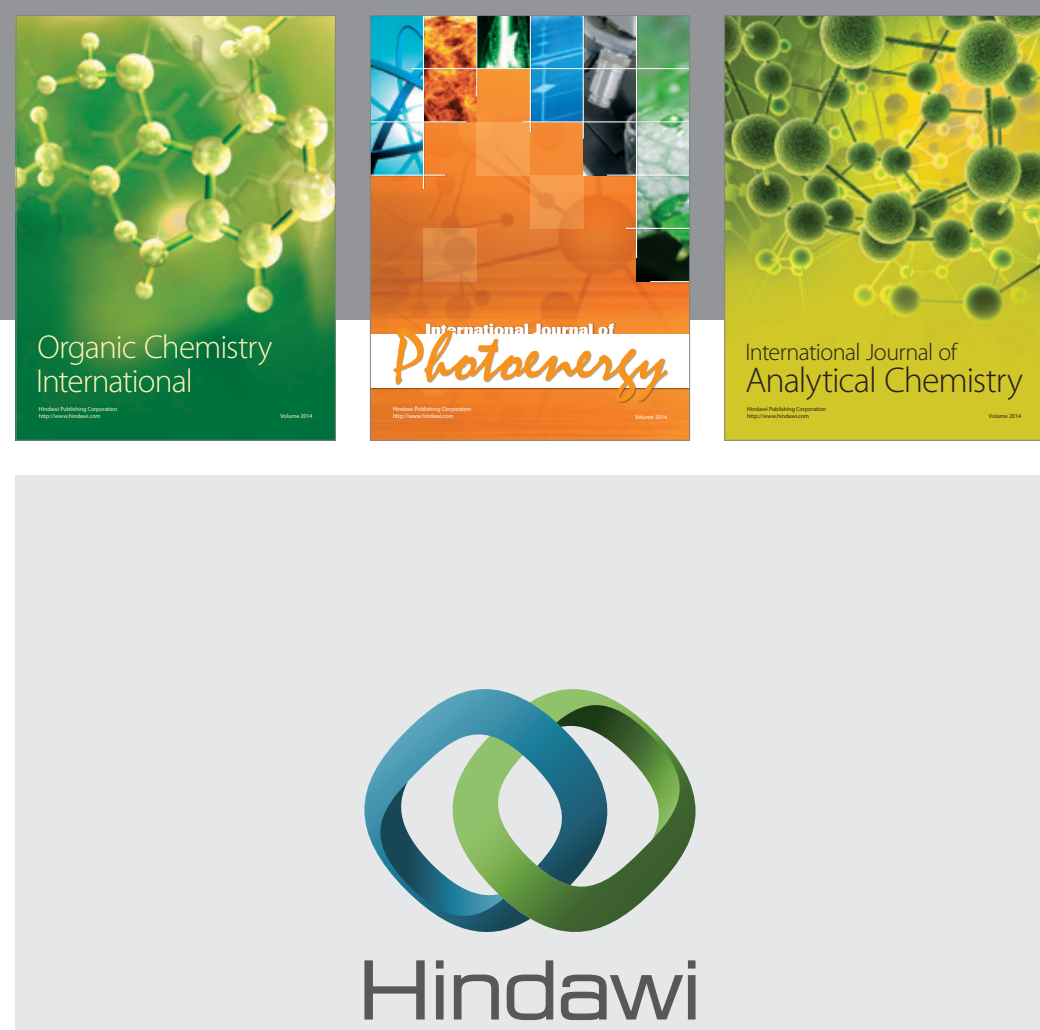

Submit your manuscripts at

http://www.hindawi.com
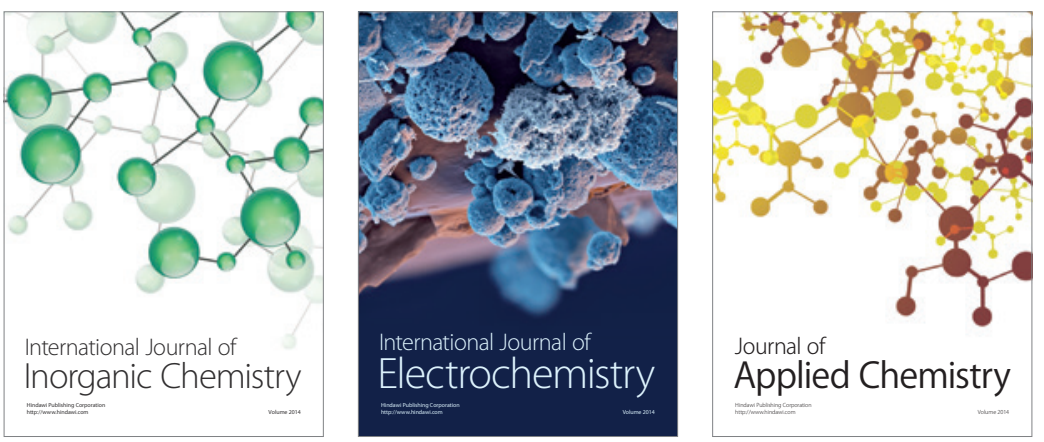

Journal of

Applied Chemistry
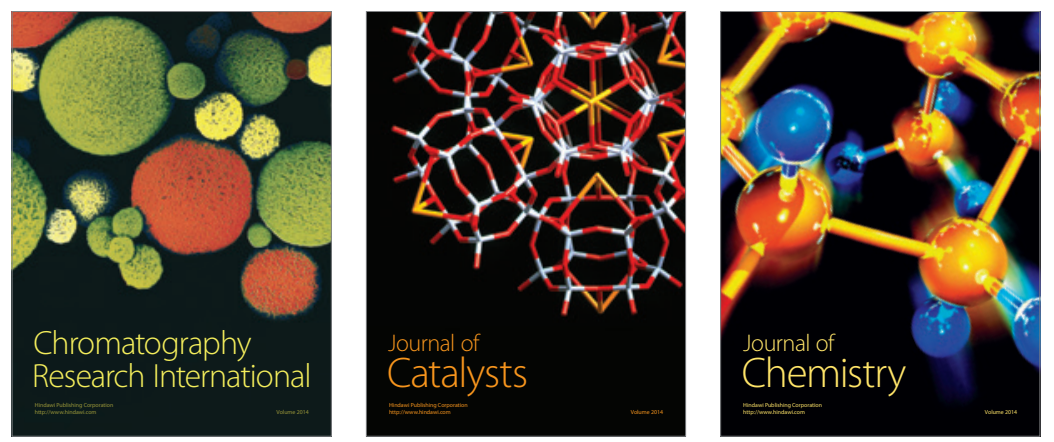
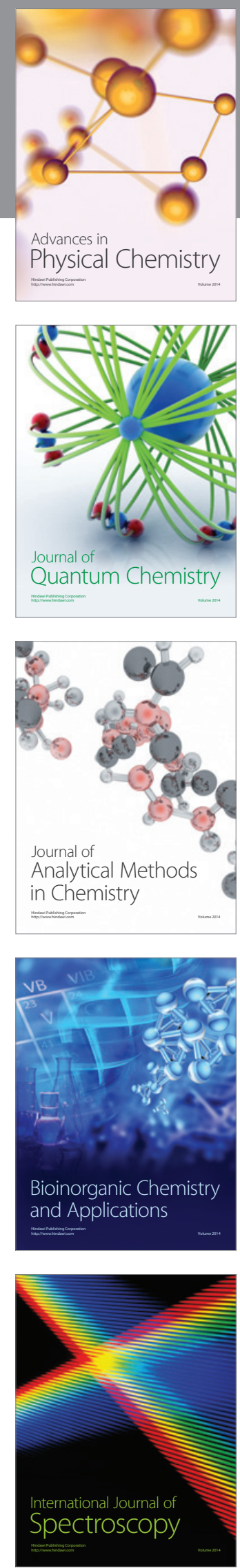